\title{
Introduction to the Special Issue: Highlighting AERA's Online Teaching and Learning SIG 2020
}

\author{
Sally Meech \\ Jennifer Richardson \\ Purdue University \\ Karen Swan \\ University of Illinois - Springfield
}

The American Educational Research Association (AERA), founded in 1916, comprises an international membership spanning more than 96 countries. AERA's mission is to advance knowledge, scholarly inquiry, and the use of research to improve education practice and policy. The organization's more than 25,000 members work in fields such as higher education, research institutes, schools, government agencies, corporations, and nonprofit organizations. AERA members include professionals who are committed to rigorous and accessible research. Through its dissemination, members' research helps to describe, understand, and explain learning in diverse contexts, and develop new tools and methods.

While typically the AERA annual meeting gathers together thousands of educational researchers to share their scholarship, due to the COVID-19 pandemic, the 2020 meeting was cancelled. Despite this unexpected change, the organization's members have remained committed to disseminating their work through the Online Paper Repository and the new year-round, webbased Interactive Presentation Gallery. This years' theme, "The Power and Possibilities for the Public Good: When Researchers and Organizational Stakeholders Collaborate" generated submissions across the organization's 12 disciplinary divisions and 155 special interest groups (SIGs). The SIG on Online Teaching and Learning (OTL) is among the largest of the AERA SIGs.

The purpose of the OTL SIG is to provide a forum for interested AERA members to discuss issues and advance research relevant to online teaching and learning. Members include researchers and practitioners from a variety of fields, resulting in an eclectic and vibrant group of professionals with the shared goal of bridging research and practice to advance the understanding of education. The papers in this issue represent a select group of submissions from the AERA 2020 annual meeting. For more information about the OTL SIG see: https://www.aera.net/SIG035/OnlineTeaching-and-Learning-SIG-35

The eight papers included in this special edition consist of a variety of research topics, designs, and frameworks. The special edition is arranged in four categories: affordances of digital technologies for student learning; intentional design and delivery of online courses to support student needs and learning outcomes; strategies to predict and support student success; and online program quality.

The first category of studies investigated the use of digital technologies, both in a general sense and from the perspective of specific technologies, to support teaching and learning. In "Virtually Authentic: Graduate Students' Perspective Changes Toward Authentic Learning While 
Collaborating in a Virtual World," Songhee Han and Paul Resta detailed how using Second Life as a computer supported collaborative learning environment between two culturally different groups of students aided in building community and developing collaborative learning, described as hallmarks of authentic learning. Employing an intrinsic case study design, the authors investigated the changes in participants' self-reported perspectives throughout stages of the course as they designed and then participated in Second Life learning activities. The authors findings included that authentic learning was facilitated by students taking on multiple roles (i.e., designer and learner) during the course; technologically mediated social presence; and an evolving sense of community in which learners moved from a sense of novelty and team work to one of meaningful engagement and whole-class cohesion.

In the next study, "Exploring Student Perceptions of Flipgrid in Online Courses," Patrick Lowenthal and Robert Moore investigated the use of Flipgrid as a means of addressing the constraints of text-only discussions and the application's potential to improve students' interaction and communication. In the exploratory study, including participants who were primarily educators or instructional designers, the authors concluded that the participants found Flipgrid beneficial and easy to use and perceived that the application improved social presence and increased peer connections. Noting a challenge, however, Lowenthal and Moore's study also aligns with previous research showing that some students are reluctant to use video recordings.

The final paper in this section, Alex Kumi Yeboah, Lydiah Kirambi, Anthony Sallar, and Kim Yanghyun's "Exploring Digital Technologies From the Perspective of Diverse Learners in Online Learning Environments," used a qualitative design with semi-structured interviews to investigate 46 participants' perspectives about technologies that facilitated and promoted positive and academically supportive experiences. The subjects included a diverse group of male and female undergraduate students with varied ethnicities, cultural backgrounds, and educational programs. In detailing their findings, the authors reported on students' use of specific technologies, and, aligning the results with a constructivist view of learning, indicated multiple affordances for student learning experiences.

Next, two studies addressed the design and delivery of online courses to support student outcomes. "Asynchronous Online Discussions During Case-Based Learning: A Problem-Solving Process," a study by Adrie Koehler, Zui Cheng, Holly Fiock, Shamila Janakiraman, and Huanhuan Wang, used an exploratory multiple-case study design to investigate six graduate students' intentional approaches to asynchronous discussions. Framing discussions in case-based learning as ill-structured problems, the authors contended that learners must develop goals and apply strategies to benefit from the discussions. The results of the study showed that in sociallyconstructed learning environments, instructors may need to provide additional support to students in co-constructing understanding; articulating participation goals; developing an understanding of the value of discussions; socially regulating learning; and encouraging students to revisit and reflect on previous posts.

Mei Jiang and Katie Koo's article, "Emotional Presence in Building an Online Learning Community Among Non-Traditional Graduate Students," investigated the role emotion played in the educational experiences of 47 working-professional students enrolled in online MS and $\mathrm{PhD}$ programs in education. Using three survey instruments and open-ended responses, the authors reported the results with a combination of statistical analyses and content analysis. The results showed that emotional presence was distinct and more unfavorably represented than other presences in the Community of Inquiry framework; was a powerful element in students' 
discussions of their learning experiences; and significantly predicted student satisfaction. The authors concluded that the results support the importance of relationship building and providing emotional support in the design and delivery of online programs.

The next studies explored strategies to predict and support student success. "AcademicFamily Integration: How do Men and Women in Distance Education and Residential Doctoral Programs Integrate Their Degree and Family?" by Amanda Rockinson-Szapkiw and Jessica Herring Watson drew on work-family theory and applied this concept to investigate three elements of academic-family balance of 177 doctoral students. Employing a causal-comparative research design, the results of the study showed that students in distance education programs were less satisfied in their ability to integrate their family and academic lives and indicated they had significantly less ability to establish boundaries between the two domains. Conversely, residential students reported higher perceptions of interference between family and academic responsibilities. In terms of gender, women's overall rating of academic-family balance was lower, with a moderate effect size. The authors recommended institutional strategies and faculty and student actions to assist in addressing academic-family balance for doctoral students.

Hsiang-yu Chien, Oi-Man Kwok, Yu-Chen Yeh, Noelle Wall Sweany, Eunkyeng Baek, and William Alex McIntosh's "Identifying At-Risk Online Learners by Psychological Variables Using Machine Learning Techniques" contended that psychological variables are an important component in determining students' needs and readiness for online learning. Using different types of predictive modeling and 225 students across three semesters, the authors proposed a predictive model for online learner success and investigated the differences in predictive accuracy between two machine learning approaches. Results showed that the random forest technique predicted student success more accurately and with the fewest number questions. The authors identified four questions that may be used to screen and identify at risk students.

Finally, one study looked at the quality of online programs. "Evaluating Online Course Quality: A Study on Implementation of Course Quality Standards," by Whitney Zimmerman, Barbara Altman, Bethany Simunich, Kay Shattuck, and Barbara Burch, used data from 5,436 reviews of courses developed using Quality Matters (QM) standards to investigate factors that impact inter-institutional peer reviews. The study framed the research within a determinant framework and design-based implementation research to investigate the intervention, implementation, and outcomes of specific quality assurance efforts. Results indicated that courses designed by developers trained in QM standards, designed to meet QM standards, and prereviewed at the institutional level met QM standards in an initial inter-institutional course review at a significantly higher rate. The authors proposed that three activities - faculty training, intentional design, and internal review - may represent stages in a continuous improvement model for external benchmarking.

We would like to extend our special thanks to OLJ editor-in-chief Peter Shea, OLJ managing editor Sturdy Knight, and OTL SIG chair Ana-Paula Correia, OTL SIG program chair Mary Rice, and all of our authors for their efforts in making this special issue possible. We hope you enjoy and learn as much from these articles as we did. 
Information about the editors:

- Sally Meech, Doctoral Student, Learning Design and Technology program, Curriculum and Instruction Department, Purdue University; sally@purdue.edu

- Jennifer C. Richardson, Professor, Learning Design and Technology program, Curriculum and Instruction Department, Purdue University; jennrich@purdue.edu

- Karen Swan, Stukel Professor of Educational Leadership, University of Illinois Springfield; kswan4@uis.edu 